\title{
ĐIỀU TRA CƠ BẢN VỀ ĐẤT ĐAI CẦN TIẾP CẬN DƯỚI GÓC ĐỘ TÀI NGUYÊN
}

\author{
NGUYẼ̃N PHI SƠN(1), NGUYẼ̃N ANH TUÂN(2), NGUYẼN THANH THUỶ(1) \\ (1) Viện Khoa học Đo đạc và Bản đồ \\ ${ }^{(2)}$ UBND phường Khương Trung, Đống Đa, Hà Nội
}

\section{Tóm tắt:}

Đất đai là tài sản quốc gia, là tư liệu sản xuất chủ yếu, là đối tượng lao động đồng thời cũng là sản phẩm lao động. Đất đai được xếp vào dạng tài nguyên hữu hạn, hiện hữu mà mỗi quốc gia luôn quan tâm, kiểm soát chặt chẽ về chất lượng, số lượng. Từ trước đến nay hoạt động điều tra cơ bản về đất đai chủ yếu là thống kê, kiểm kê về số lượng mà chưa có điều kiện để điều tra, đánh giá về chất lượng và nhiều thuộc tính khác của đất đai một cách đồng bộ và thống nhất, chưa hình thành được tiêu chuẩn, tiêu chí về các thành phần của tài nguyên đất. Trong bài báo này sẽ đề cập đến sự cần thiết của việc xây dựng bộ tiêu chí về thuộc tính của đất (Soil), đất đai (Land) dưới cách tiếp cận là tài nguyên, cơ sở xác lập các thành phần của tài nguyên đất, nhằm cung cấp một cái nhìn tổng quan hơn về đất đai và tạo lập cơ sở lý luận phục vụ hoạt động điều tra cơ bản về đất đai trong thời gian tới.

\section{1. Đặt vấn đề}

Tài nguyên khoáng sản, tài nguyên nước, tài nguyên đất, tài nguyên biển đảo, tài nguyên khí hậu là 5 nhóm tài nguyên hiện diện, có tác động trực tiếp đến con người và sự phát triển kinh tế, xã hội của đất nước, là các tài nguyên thuộc lĩnh vực quản lý của Bộ Tài nguyên và Môi trường. Trong đó tài nguyên đất là một tài nguyên đặc biệt, vừa là công cụ, vừa là tư liệu sản xuất, vừa là nguồn lực thúc đẩy sự phát kinh tế, và là nơi sinh sống và hoạt động của con người. Việc kiểm soát các quá trình khai thác, sử dụng đất đai là việc làm quan trọng của các cấp quản lý và là trách nhiệm của mỗi người dân. Từ trước đến nay hoạt động điều tra cơ bản về đất đai như: thống kê, kiểm kê; điều tra, đánh giá đất đai; đều thực hiện không đồng thời,với chu kỳ khác nhau và ở những thời điểm khác nhau, đặc biệt chưa dựa trên một đơn vị đất đai hợp lý. Một số chỉ tiêu khác của đất đai do nhiều ngành thực hiện, nhiều thuộc tính của đất đai chưa được thống kê, kiểm kê, kiểm tra, giám sát, quản lý biến động một cách thống nhất, đồng bộ, đồng thời, bởi chúng ta chỉ tiếp cận các thuộc tính của đất đai ở những khía cạnh theo mục tiêu nhất định mà chưa xem xét ở góc độ đất đai là tài nguyên...., vì vậy việc đưa ra một tiêu chuẩn chung cho điều tra đất đai dưới góc độ tài nguyên sẽ cho phép chúng ta xác lập mỗi đơn vị tài nguyên với đầy đủ thông tin thuộc tính, đảm bảo cho việc kiểm soát và đánh giá tài nguyên về số lượng, chất lượng và tiềm năng một cách đầy đủ. Nhằm đáp ứng yêu cầu của các cấp quản lý trong kiểm đếm tài nguyên, định hướng sử dụng bền vững, hài hòa giữa phát triển kinh tế và khai thác tài nguyên.

\section{Sự cần thiết phải tiếp cận đất đai dưới góc độ tài nguyên}

Tài nguyên là thành phần không thể thiếu, được khai thác, sử dụng phục vụ cuộc sống và sự phát triển của xã hội loài người. Với mỗi quốc gia, dân tộc, tài nguyên là nguồn tài sản, nguồn lực, nguồn vốn tự

\footnotetext{
Ngày nhận bài: 07/12/2016, ngày chuyển phản biện: 08/12/2016, ngày chấp nhận phản biện: 16/12/2016, ngày chấp nhận đăng: 19/12/2016
} 
nhiên đặc biệt quan trọng để xây dựng và phát triển đất nước. Quản lý, khai thác sử dụng như thế nào phụ thuộc vào từng giai đoạn lịch sử và phụ thuộc vào hoạch định chiến lược sử dụng tài nguyên của mỗi quốc gia.

Quản lý tài nguyên bao gồm việc đưa ra các kế hoạch, các phương hướng chiến Iược cụ thể, các biện pháp quy hoạch, cùng với các chế tài phù hợp, nghiêm khắc nhằm giúp cho công việc khai thác, sử dụng và bảo vệ tài nguyên một cách hợp lý, hiệu quả và mang lại lợi ích tối ưu. Trong các văn liệu hiện nay thường nhấn mạnh về mặt sử dụng "bền vững" tài nguyên, vậy đất đai có cần sử dụng bền vững không? và câu trả lời là: có. Từ mục tiêu bền vững đã đặt ra nhiều bài toán cho phép chúng ta tìm ngược lại các giải pháp trong khai thác tài nguyên đồng bộ với bảo vệ tài nguyên.

Việt Nam là một trong những quốc gia có nguồn tài nguyên thiên nhiên phong phú và đa dạng. Tuy nhiên, do quản lý thiếu đồng bộ, công nghệ khai thác lạc hậu, nhất là việc khai thác, sử dụng nhiều nhóm tài nguyên chưa hợp lý... đang là những nguyên nhân dẫn đến lãng phí nguồn lực quốc gia, tài nguyên bị suy thoái, cạn kiệt, đe dọa sự phát triển bền vững của đất nước. Một trong những nguyên nhân đó là chúng ta chưa đủ thông tin đồng bộ về tài nguyên, hầu hết các ngành, các lĩnh vực đều phải tiến hành khảo sát, điều tra cơ bản về địa chất, về đất đai, về tài nguyên nước, môi trường khí hậu.... trước khi tiến hành các hoạt động $\mathrm{KT}-\mathrm{XH}$ khác, đôi khi các thông tin, dữ liệu thu thập được không đồng bộ, tốn kém và trùng lặp. Bên cạnh đó, công tác quản lý tài nguyên phải bảo đảm được các yêu cầu như sự hiểu biết ngày càng đầy đủ hơn, toàn diện hơn về tiềm năng, trữ lượng, giá trị của các nguồn tài nguyên; Nói như vậy, việc kiểm soát tài nguyên đảm bảo cho công tác quản lý rất cần đầy đủ các thông tin về thuộc tính, số lượng, chất lượng, hiện trạng, biến động tài nguyên phục vụ hỗ trợ ra quyết định, làm cơ sở cho cân đối nguồn lực tài nguyên cho phát triển kinh tế - xã hội; bảo đảm khai thác, sử dụng tài nguyên hợp lý, hiệu quả và bền vững; bảo vệ, phục hồi, phát triển các nguồn tài nguyên tái tạo. Nhà nước cũng đã quan tâm đầu tư nhiều cho công tác công tác điều tra cơ bản, kiểm kê, thống kê, đánh giá các nguồn tài nguyên. Các chủ trương, chính sách, pháp luật về quản lý tài nguyên liên tục được đổi mới, hoàn thiện, đáp ứng yêu cầu của quá trình phát triển kinh tế - xã hội; sự nghiệp công nghiệp hóa, hiện đại hóa đất nước.... Đất đai cũng là một thành phần nằm trong bối cảnh chung của tài nguyên quốc gia như vậy.

Đất đai đang bị biến động mạnh mẽ sau 30 năm đổi mới, chuyển đổi cơ cấu, đất nông nghiệp đang ngày một thu hẹp, chuyẻn qua phục vụ cho công nghiệp và xây dựng hạ tầng. Đất bị nhiễm mặn, khô hạn, sa mạc hóa, bạc mầu ngày càng tăng thêm. Quản lý nhà nước về đất đai là nhu cầu khách quan là công cụ bảo vệ và điều tiết các lợi ích gắn liền với đất đai. Trong kinh tế đất việc hình thành thị trường bất động sản cũng đòi hỏi các thông tin đầy đủ, minh bạch và chi tiết về thuộc tính của đất đai. Việc kiểm đếm số lượng, sự phân bố và sử dụng đất, chất lượng đất, môi trường đất đối với mỗi đơn vị tài nguyên đất trở nên vô cùng quan trọng trong hoạt động quản lý.

Thực trạng hoạt động quản lý và sử dụng đất dưới góc độ đất (Soil) hay đất đai (Land) đang đặt ra nhiều tồn tại mà cho đến nay chúng ta cần nhìn rộng hơn, tổng quan hơn về đất dưới dạng một tài nguyên đặc biệt:

i) Đất đai mặc dù đã được điều tra, đánh giá song chỉ thống kê được thông tin cơ bản, thiếu thông tin quan trọng để có thể lượng hóa được giá trị kinh tế cũng như định hướng cho sử dụng đất và đánh giá tiềm năng. Thống kê định kỳ hàng năm, kiểm kê định kỳ 5 năm, nhưng chúng ta mới cung cấp được một phần về thuộc tính của 
đất đai chưa nhìn nhận đất và đất đai một cách toàn diện, đồng bộ và đầy đủ, hay nói cách khác việc quan tâm về số lượng chưa đồng bộ với chất lượng.

ii) Công tác lập quy hoạch, kế hoạch sử dụng đất còn nhiều bất cập, thiếu cơ sở khoa học, nhiều nơi đất đai, nguồn lực tài nguyên không được khai thác, sử dụng đúng mục đích, cho hiệu quả thấp. Việc định giá đất đai dưới góc độ tài sản còn nhiều bất câpp. Phương pháp xác định giá dựa trên các yếu tố, thông tin giả định, dự báo, có tính chủ quan, không phù hợp với điều kiện của Việt Nam... Những bất cập này xuất phát từ hệ quả của thiếu thông tin về đất đai, không đủ thông tin để đánh giá tiềm năng, không đồng bộ để đảm bảo độ tin cậy.

iii) Việc kiểm đếm số lượng, chất lượng, phân bố tài nguyên cần phải dựa trên một đơn vị tài nguyên nhất định. Trong thống kê, kiểm kê chúng ta dựa trên "thửa đât" là đơn vị, trong điều tra, đánh giá đất đai chúng dựa trên nhiều loại "khoanh đất", trong kinh tế đất chúng ta dựa trên "vùng giá trị" ...việc thống nhất "đơn vị đo" trong các nhiệm vụ này cần phải tiếp cận đối tượng nhiên cứu ở một góc độ tổng thể hơn.

iv) Hiệu quả sử dụng đất chưa được đánh giá đầy đủ, các tiêu chuẩn nguồn lực về sức sản xuất của đất đai chưa được hình thành đầy đủ, không xem xét đất đai một cách hệ thống, quản lý và sử dụng đất sẽ thiếu hụt thông tin và phiến diện... điều này xuất phát từ quản trị đất đai chưa hiệu quả.

\section{Cơ sở xác lập các thành phần thuộc tính của tài nguyên Đất}

Chúng ta cần phân biệt giữa thuật ngữ "đất" và "đất đai", đất đai bao gồm toàn bộ các thuộc tính của đất. Theo FAO (1995), các chức năng của đất đai đối với hoạt động sản xuất và sinh tồn của xã hội loài người được thể hiện qua các mặt sau: sản xuất, môi trường sự sống, điều chỉnh khí hậu, cân bằng sinh thái, tồn trữ và cung cấp nguồn nước, dự trữ (nguyên liệu khoáng sản trong lòng đất); không gian sự sống; bảo tồn, lịch sử; vật mang sự sống; phân dị lãnh thổ. Theo Lê Huy Bá (2000), đất đai là kết quả của mối quan hệ tổng hoà giữa đất và hoạt động kinh tế xã hội của con người trong cộng đồng dân tộc trên một lãnh thổ nhất định; về mặt không gian thì đất đai bao gồm cả phần bề mặt với không gian bên trên và bề sâu trong lòng đất. Đất đai thuộc phạm trù địa lý - kinh tế. Đất là lớp bề mặt trái đất hiểu theo nghĩa rộng hơn so với khái niệm thổ nhưỡng, đất thuộc phạm trù địa lý tự nhiên.

Tài nguyên đất được hiểu bao gồm đất, đất đai và các thuộc tính khác. Thuộc tính tự nhiên: bao gồm các đặc tính không gian như diện tích, hình thể, chiều dài, chiều rộng và vị trí cùng với các đặc điểm về địa chất, địa chấn, địa hình, địa mạo và các tính chất sinh lý hóa của đât. Đây là các đặc tính phản ánh chất lượng tự nhiên của đất đai đáp ứng các nhu cầu vật chất của con người; Thuộc tính xã hội: là vị thế của đất đai - là hình thức đo sự mong muốn về mặt xã hội gắn với đất đai tại một vị trí nhất định, là tiềm năng không thể định lượng chính xác. Vị thế được hiểu là tổng hòa các quan hệ xã hội được hình thành từ những tương tác thị trường và phi thị trường. Vị thế xã hội của đất đai đáp ứng các nhu cầu xã hội của con người.Chất lượng tự nhiên của đất đai là đại lượng vật lý hữu hình. Nhưng ngược lại vị thế xã hội là đại lượng vô hình chỉ có thể xác định gián tiếp thông qua các biến hữu hình. Đất đai có khả năng tái tạo và nâng cao chất lượng tự nhiên và vị thế xã hội thông qua hoạt động đầu tư của con người. Ví dụ, đầu tư cải tạo độ phì của đất, phát triển cơ sở hạ tầng giao thông, đầu tư tiếp thị quảng cáo bất động sản,...

Dưới cách tiếp cận đất đai là tài nguyên, chúng ta có thể kể đến 3 thành phần chính của tài nguyên gồm: Phân bố tài nguyên; Chất lượng và trữ lượng tài nguyên; Khai 
thác và sử dụng tài nguyên.

i) Phân bố tài nguyên đất (Land distribution) được hiểu là phân bố trong không gian của các loại đất trong quỹ đất quốc gia. Cần phân biệt 3 không gian: không gian tự nhiên (còn gọi là không gian địa lý tự nhiên); không gian kinh tế - xã hội (còn gọi là không gian địa lý - kinh tế) và không gian tâm lý. Khái niệm vị thế được hiểu như là tổ hợp của 3 không gian nêu trên, tức là hình ảnh hay vị trí của các đối tượng địa lý, kinh tế xã hội trong tâm trí con người. Vị thế là một đại lượng mang tính lịch sử, nó có thể thay đổi theo trào lưu, tâm lý, thị hiếu của người tiêu dùng, còn vị trí là cố định (bất biến). Nhờ tính khả biến của vị thế mà mọi thửa đất đều có giá trị khác nhau. Vị trí đất đai là cố định, nên lợi ích và giá trị của đất đai gắn liền với từng vị trí cụ thể, chịu tác động của yếu tố vùng và khu vực như: Những yếu tố tự nhiên; Điều kiện kinh tế; Tính chất xã họi; Điều kiện môi trường. Tính dị biệt: Những điểm khác nhau về vị trí thửa đất, diện tích, hình thể, cảnh quan,... khác nhau về các đặc tính chất lượng tự nhiên và vị thế xã hội làm cho mỗi thửa đất đều có đặc điểm riêng, tạo nên tính dị biệt của đất đai.

ii) Chất lượng tài nguyên đất (Land Quanlity - LQ) là tính chất phức tạp của đất đai thể hiện những mức độ thích hợp khác nhau cho một loại hình sử dụng đất cụ thể. Đặc tính đất đai thể hiện trên các bản đồ đơn vị đất đai (LMU) chính là câu trả lời trực tiếp cho các yêu cầu sử dụng của các loại hình sử dụng đất (LUT). Thông thường LQ phản ánh nội tại của rất nhiều tính chất đất đai, các ví vụ về đặc tính đất đai có thể có là: Mức độ xói mòn, chế độ nhiệt, chế độ ẩm, khả năng thoát nước, chế độ cung cấp dinh dưỡng, mức độ sâu của lớp đất, địa hình ảnh hưởng đến xói mòn hoặc cơ giới hoá, mức độ ngập, độ phì nhiêu của đồng cỏ, giao thông thuận lợi,....Như vậy chất lượng đất đai chính là các thuộc tính của đất đai tác động đặc biệt đến tính thích hợp của đất đó đối với các loại sử dụng đất riêng biệt. Chất lượng đất là một thành phần quan trọng của tài nguyên đất.

iii) Khai thác, sử dụng tài nguyên đất (Land Use) thể hiện ở các loại hình sử dụng đất đai, loại đất đai và các nguyên tắc phân loại tài nguyên đất đai. Loại hình sử dụng đất đai: là một thửa đất cụ thể có ranh giới rõ ràng trên thực địa được sử dụng thường xuyên có hệ thống cho một nhu cầu nhất định của con người. Ranh giới thửa đất được xác định thông qua sự tương phản giữa các loại hình sử dụng khác nhau. - Loại đất đai: tập hợp từ các thửa đất có mục đích sử dụng chung cho các hoạt động kinh tế xã hội của con người, ranh giới của loại đất đai là ranh giới quy ước, được xác định bằng các mốc giới địa chính, hay xác định trên bản đồ quy hoạch. - Quỹ đất đai: tập hợp từ các loại đất đai. Là toàn bộ diện tích đất đai các loại trong phạm vi lãnh thổ quốc gia được gọi là quỹ đất đai quốc gia; trong phạm vi lãnh thổ các cấp hành chính thì được gọi là quỹ đất đai cấp hành chính tương ứng, trong phạm vi ranh giới sử dụng của một chủ thể nào đó thì được gọi là quỹ đất đai của chủ thể đó. Quỹ đất đai quốc gia hình thành và phát triển cùng với tiến trình lịch sử của dân tộc và các hoạt động KT-XH trong cộng đồng đó, trong quá trình đó phạm vi đất đai dần dần được mở rộng hay thu hẹp. Các loại đất đai được hình thành, xuất hiện phù hợp với nhu cầu hoạt động KT-XH của con người. - Trước tiên là phải xác định được quỹ đất đai ở trạng thái động hay trạng thái tĩnh tùy thuộc vào quan điểm nhìn nhận của nhà nghiên cứu, từ góc nhìn động thái hay tĩnh tại. - Quỹ đất đai được hình thành trong quá trình phát triển sản xuất của con người, do đó quỹ đất đai là một trạng thái động: vận động và thay đổi theo các nhu cầu phát triển kinh tế - xã hội. Đây chính là căn cứ để xác định nguyên tắc phân loại quỹ đất đai quốc gia. Đây là thuộc tính số lượng của tài nguyên và được nhà 
nước kiểm đếm hàng năm và kiểm kê 5 năm.

\section{Về khái niệm đơn vị tài nguyên đất:}

Vấn đề đặt ra là đơn vị của tài nguyên cần được xem xét dưới góc độ nào? Trong công tác quản lý đất đai không có sự thống nhất về nguyên tắc phân loại quỹ đất đai quốc gia. Theo Luật đất đai 1993 thì loại đất đai được xác định theo nguyên tắc quan hệ, nhưng Luật 2003 và Luật 2013 thì lại xác định theo nguyên tắc tương đồng. Chúng ta cần phải xác định loại đất đai bằng nguyên tắc quan hệ, tức theo mối quan hệ qua lại giữa các thửa đất. Quan hệ này có nguồn gốc từ sự tương tác giữa các hoạt động kinh tế - xã hội của con người, hay còn gọi là vị thế đất đai (hiểu vị thế là tổng hòa quan hệ xã hội). Điều này sẽ được làm rõ ở phần sau đây khi nghiên cứu các quy luật phân vùng sử dụng đất đai, thấy được mối tương quan giữa mục đích sử dụng và vị thế đất đai. Các thửa đất kết hợp với nhau tạo thành loại đất theo 2 nguyên tắc: Tương đồng (giống nhau); Quan hệ (hệ thống). Trong nghiên cứu phân loại các thành phần của một tập hợp bất kỳ người ta sử dụng 2 nguyên tắc khác nhau cho các trạng thái khác nhau của tập hợp. Nguyên tắc quan hệ cho tập hợp động, nguyên tắc tương đồng cho tập hợp tĩnh. Đứng ở góc độ hoạt động kinh tế thì các loại đất được xác định theo nguyên tắc quan hệ. Ví dụ: theo nguyên tắc quan hệ đất giao thông nội đồng được xếp vào loại đất nông nghiệp; giao thông nội bộ khu dân cư được xếp vào đất khu dân cư. Trong quá trình điều tra đánh giá tài nguyên đất đai đều dựa trên nền tảng căn bản là sức sản xuất của đất thể hiện bằng các chỉ tiêu tự nhiên như: Về mặt thổ nhưỡng gồm: Thành phần cơ giới, độ chua, tính chất hoá học, độ phì nhiêu, độ dày tầng đất, chất lẫn vào (kết von, sỏi sạn,...), hiện tượng gley,...; ; Về điều kiện tự nhiên khác như địa hình, khí hậu, chế độ nước, đất ngập nước... Các đánh giá đất đều dựa trên mức độ thích hợp hay yếu tố hạn chế của từng loại đất để phân hạng.

Như vậy có thể thấy rằng, các vùng tự nhiên mang tính đồng nhất về tất cả các thuộc tính của đất đai được gọi là các đơn vị đất đai (Land unit). Để mô tả một đơn vị đất đai chúng ta cần có các đặc tính đất đai (Land Characteristics). Quay trở lại xem xét các thành phần của tài nguyên đất chúng ta cần phải làm rõ các thuộc tính (tự nhiên, xã hội và vị thế) để đưa ra được đơn vị đất thỏa mãn tính tương đồng cũng như tính quan hệ của tài nguyên đất.

Để tiến hành được các hoạt động điều tra cơ bản về đất đai dưới dạng là tài nguyên, chúng ta cần phải giải quyết những vấn đề cốt lõi sau đây:

- Xác lập đầy đủ cơ sở khoa học và lý luận về đất đai dưới góc độ tài nguyên.

- Hình thành được bộ tiêu chí, tiêu chuẩn về các thành phần của tài nguyên đất.

- Ứng dụng công nghệ và phát triển các kỹ thuật trong điều tra cơ bản về tài nguyên đất một cách đồng bộ, gắn việc điều tra cơ bản với việc giám sát biến động tài nguyên một cách hiệu quả, nhanh chóng, khách quan và chính xác.

Có được những thông tin về tài nguyên một cách toàn diện như vậy sẽ góp phần cho hoạt động quản lý như: quy hoạch, kế hoạch; thống kê, kiểm kê; điều tra, đánh giá; kinh tế đất đai... và hoạt động sử dụng đất như: thích nghi, chuyển đổi cơ cấu, hiệu quả sử dụng....nâng cao được chất lượng và hiệu quả của thông tin đất đai.

\section{Kết luận và kiến nghị}

Cần thống nhất quan điểm cũng như cách tiếp cận về đất đai, trong điều tra cơ bản về đất đai cần phải được tiếp cận dưới góc độ là tài nguyên. Thực tiễn hoạt động quản lý cũng như hoạt động sử dụng đất, đặc biệt là xác định tiềm năng, rất cần 
những thông tin đồng bộ, đầy đủ và được quy chiếu trong một chỉnh thể thống nhất. Bên cạnh các hoạt động điều tra hiện nay mới quan tâm về số lượng cần phải đồng bộ hóa các yêu cầu về chất lượng và vị thế của đất đai. Điều này đòi hỏi những nghiên cứu tổng hợp, cơ sở khoa học và thực tiễn của đất đai dưới góc độ đất đai là tài nguyên, để từ đó đất đai được ứng xử với tư cách là nguồn lực cho phát triển kinh tế xã hội, khai thác, sử dụng có hiệu quả các nguồn lực từ tài nguyên đất đai. $\mathrm{O}$

\section{Tài liệu tham khảo}

[1]. Lê Huy Bá. 2007 "Môi trường tài nguyên đất". NXB giáo dục Việt Nam;

[2]. Nguyễn Đình Bồng. 2007. Quy hoạch sử dụng đất ở nước ta trong giai đoạn hiện nay - thực trạng và giải pháp. Hội thảo khoa học về quy hoạch sử dụng đất. Viện nghiên cứu Địa chính 2007;
[3]. Chính phủ. 2012. Quyết định số 1892/QĐ-TTg ngày 14/12/2012 về việc phê duyệt "Đề án nâng cao năng lực quản lý nhà nước ngành Quản lý đất đai giai đoạn 2011 -2020 ".

[4]. Nguyễn Dũng Tiến 2009. Nghiên cứu thực trạng và giải pháp hoàn thiện hệ thống quy hoạch sử dụng đất đai trong thời kỳ công nghiệp hóa. Báo cáo tổng kết đề tài khoa học công nghệ cấp bộ, Bộ Tài nguyên và Môi trường.

[5]. Nguyễn Thị Thu Trang. 2015. "Đẩy mạnh hoạt động điều tra đánh giá đất đai trong chiến lược phát triển bền vững ứng phó biến đổi khí hậu". http://www.gdla.gov.vn/.

[6]. Nguyễn Phi Sơn, 2014. "Vùng giá trị đất và ứng dụng trong địa chính". Tạp chí khoa học Đo đạc và Bản đồ số 19. Tháng 3/2014. Tr15-20.O

\section{Summary}

\section{Fundamental investigations of land need to view in a resource perspective}

Nguyen Phi Son, Nguyen Thanh Thuy

Institute of Geodesy and Cartography

Nguyen Anh Tuan

Ward People's Committee of Khuong Trung, Dong Da Dist, Hanoi

Land is considered as a national asset as well as a major productive force. It is notonly the subjects but also the products of labor. Land is classified as a limited andvisible resource that every-country needs to quantitatively and qualitativelycontrol. Investigative activities have been mostly quantitative inventories withoutqualitative and informative inquiries synchronously. The criteria and standards forthe elements of land resource have not been carefully built. This paper will discussthe significance of building attribute criteria for soil and land with regard to naturalresource approach. The article will also mention the foundations of land resourceelements in order to give a full view of such resource, and to create theories forfundamental investigation of land in the near future. $O$ 